\title{
Missed appendicitis in primary care: lessons learned
}

\author{
Volume 7 Issue 4 - 2016
}

\section{Introduction}

Abdominal pain is a common presenting symptom in primary care accounting for $10 \%$, whilst a clinical diagnosis of acute appendicitis can be identified by thorough clinical examination, ${ }^{1}$ but still there are many diagnostic uncertainties in more challenging cases. ${ }^{2}$

Physician's overall diagnostic accuracy reaches up to $80 \%$ of traditional history, physical examination, and laboratory tests. The ease and accuracy of diagnosis depend on many factors such as age, sex, presence of gastritis symptoms, and presence of urological symptoms. While atypical acute appendicitis presentation, the physician should order abdominal ultrasonography (accuracy rates range $71-97 \%$ ) and/ or computed tomography (CT) (accuracy rate range 93 and $98 \%)$. $^{3}$ Failure or delay in diagnosis of acute appendicitis is a common malpractice complaint in primary care.

\section{Unusual presentation of acute Appendicitis Cases in Primary Care}

Case 1: 9 years old male child presented to primary care physician with epigastric pain, vomiting and loose motion of one hour duration after eating food from the restaurant. He was screaming from abdominal pain and can't stand still. He was afebrile and abdominal examination showed no rebound tenderness /rigidity. Urine R/M shows only positive ketone, $\mathrm{CBCs}$ was not done. The diagnosis was gastroenteritis and the patient showed some improvement after fluid and symptomatic treatment. The patient discharged home, and returned back with generalized abdominal pain, but more at right iliac fossa (RIF). While on abdominal examination revealed generalize abdominal tenderness, with positive RIF rebound tenderness. Further work was done with CBCs, ESR, C- reactive protein, abdominal X ray, ultrasound and CT scan revealed acute appendicitis with perforation. Laparotomy and peritoneal lavage were done for perforated appendix.

Case 2: 23 years old man presented to primary care physician with lower pelvic pain and mild urological symptoms with infrequent vomiting, the McBurney point was negative. The urine R/M showed pyurea and hematuria. But unfortunately, there was no response to urinary tract infection (UTI) treatment. The patient appeared next day with severe abdominal pain, mostly in right lower quadrant with positive rebound, obturator and psoas signs. Appendectomy was done and the patient showed dramatic improvement of symptoms and signs.

Case 3: 28 weeks pregnant lady presented to primary care physician with severe sharp unspecified pain, mostly in right upper and lower quadrant area, with frequent vomiting and anorexia. On examination was shown restless lady, and tense abdomen. She was referred as acute abdomen with probable diagnosis acute cholecystitis. Patient was admitted and ultrasound was suggesting acute appendicitis.

Case 4: 48 years old lady presented to primary care physician with severe abdominal pain which affect her gait. She complained nausea, restlessness, bad smell from her mouth. She had lower abdominal pain with rebound tenderness. The vaginal examination was an exacerbating abdominal pain with any cervix movement. She was referred as an acute pelvic inflammatory disease (PID); but on further work up (US and CT scan) confirmed diagnosis of acute appendicitis.

\author{
Basem Abbas Al Ubaidi \\ Assistant professor in Arabian Gulf University (AGU), \\ Consultant Family Physician, Ministry of Health, Kingdom of \\ Bahrain
}

Correspondence: Basem Abbas Al Ubaidi, Assistant professor in Arabian Gulf University (AGU), Consultant Family Physician, Ministry of Health, Kingdom of Bahrain,

Email bahmedI@health.gov.bh

Received: October 25, 2016 | Published: December 16, 2016

\section{Discussion \\ Clinical presentation}

Acute appendicitis diagnosis depends on a detailed history and the organized physical examination. Acute appendicitis can mimic the presentation of many surgical, medical, gynecological and urological emergency cases (Table 1)., ${ }^{1,3,4}$

Table I Alvarado scoring scale for diagnosis of acute appendicitis. ${ }^{3}$

\begin{tabular}{ll}
\hline Alvarado score & Variable Value \\
\hline Symptoms & \\
Migration & $\mathrm{I}$ \\
Anorexia-acetone & $\mathrm{I}$ \\
Nausea-vomiting & \\
Signs & \\
Tenderness in right lower quadrant & 2 \\
Rebound pain & $\mathrm{I}$ \\
Elevation of temperature C $37.3-$ & $\mathrm{I}$ \\
Laboratory & \\
Leukocytosis $>10.0 \times 109 / \mathrm{L}$ & 2 \\
Shift to the left $>75 \%$ & $\mathrm{I}$ \\
Total* & 10 \\
\hline
\end{tabular}

History: The history of acute appendicitis can go through many sequence (stages); first central colicky peri-umbilical abdominal pain (99\%), followed by vomiting and pain migration (50\%) to the right iliac fossa (RIF). ${ }^{5}$ The pain progression results from the nonspecific initial visceral pain to more localized parietal peritoneum pain. ${ }^{6}$ Associated symptoms include anorexia (24-99\%), nausea (62-90\%), infrequent vomiting $(32-75 \%)$ to profuse vomiting (diffuse peritonitis), low grade fever (67-69\%) and constipation. ${ }^{7}$ The clinical presentations of appendicitis depend mainly on the anatomical positions (retrocaecal /retrocolic, subcaecal/pelvic and pre/postileal) of their appendix location and anatomical surrounding structures (Table 2).,3

Examination: A physician should examine suspected cases of acute appendicitis thoroughly starting the general appearance, and do vital signs, inspection, palpation, percussion, and auscultation of abdominal sounds (Table 3 ). ${ }^{1,3}$ There are two important abdominal 
tests to diagnose a case of acute appendicitis are ; first coughing and second hopping test; by asking the patient either to cough or hop upward which exacerbates abdominal pain. The physician should also, notice any muscle guarding and rigidity in $21 \%$ of the cases, and if there is maximum tenderness over McBurneys' in 26\% of the cases (Figure 1) which either verify by abdominal palpation or percussion (Figure 2) ${ }^{8}{ }^{89}$ Physician should avoid rebound tenderness to avoid disturbing the patient. The physician should elicit the four most important signs to diagnosis a case of acute appendicitis (coughing, hopping test, percussion tenderness, and guarding / rigidity) ${ }^{10}$ with high positive likehood ratio $(\mathrm{LR}+4.0){ }^{5}$

Table 2 MANTRELS score for diagnosis of acute appendicitis. ${ }^{3}$

\begin{tabular}{ll}
\hline MANTRELS score & Variable Value \\
\hline$M=$ Migration of pain to the RIF & $\mathrm{I}$ \\
$\mathrm{A}=$ Anorexia & $\mathrm{I}$ \\
$\mathrm{N}=$ Nausea and vomiting & $\mathrm{I}$ \\
$\mathrm{T}=$ Tenderness in RIF & 2 \\
$\mathrm{R}=$ Rebound pain & $\mathrm{I}$ \\
$\mathrm{E}=$ Elevated temperature & $\mathrm{I}$ \\
$\mathrm{L}=$ Leukocytosis & 2 \\
$\mathrm{~S}=$ Shift of WBCs to the left & $\mathrm{I}$ \\
Total* & $\mathrm{I} 0$ \\
Source:Alvarado., ${ }^{19}$ &
\end{tabular}

*Total score of I- 4: Appendicitis unlikely; 5 - 6: Appendicitis possible; 7 - 8: Appendicitis probable; 9 - 10:Appendicitis very probable.

Table 3 Complete examination of suspected cases of acute appendicitis

\section{General Examination}

Flushed, a fetor or is, in pain, lie still, low grade fever and tachycardia

Abdominal Examination Signs of localized/ generalized peritoneal irritation

Dunphy's sign Increased pain in the right lower quadrant with coughing

Hip flexion sign

Other peritoneal signs

Patient maintains hip flexion with knees drawn up for comfort

Rebound tenderness, hyperesthesia of the skin in the right lower quadrant

Positive Hopping Test Increased pain in the right lower quadrant with hopping

Positive Rebound Tenderness in McBurney's Point

Positive localized rebound tenderness on right lower quadrant and muscular guarding and Muscular Rigidity.

Positive Percussion Tenderness

Normal Rectal or Vaginal

Localized tenderness over percussion site at McBurney's point

examination

RIF pain on rectal/ vaginal examination may indicate a pelvic appendix

RIF Pain on palpation left iliac fossa

Pain on hyperextension of right thigh in lateral decubitus position (retroperitoneal retrocecal appendix)

Pain thigh lifting against resistant in supine position (retroperitoneal retrocecal appendix)

Positive Obturator's Sign

Pain on internal rotation of right thigh (pelvic appendix)

A physician should always perform a rectal or vaginal examination in acute abdomen; which is positive in pelvic appendicitis with Odds Ratio ${ }^{\mathrm{OR}}$ of 1.3. ${ }^{11}$ The physician should notice if there is pain in RIF when palpate LIF (Positive Rovsing's Sign) (Figure 3). ${ }^{5,9}$ Ask patient to lie in supine position with flex right hip, then ask patient to lift the right thigh whereas physician applying pressure just above the knee (Figure 4) or the physician apply a passive extension of right leg at the right hip, while the patient posture has left lateral decubitus position (Positive Psoas Sign) (Figure $5 \& 7$ ). ${ }^{5,9}$ The physician can elicit a positive Obturator Sign by applying passive flex right knee with internal rotation the right hip (Figure $6 \& 7$ )..$^{5,9}$

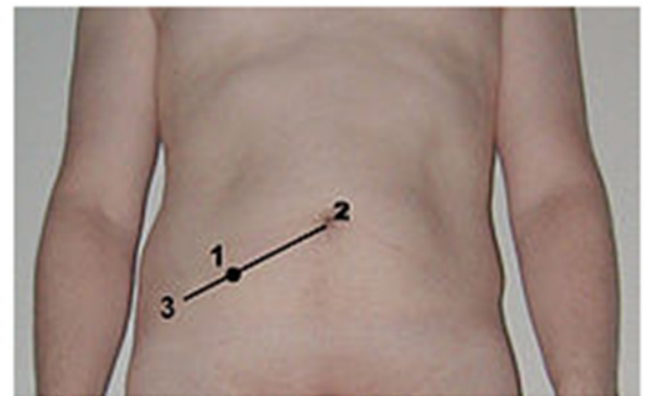

Figure I McBurneys' point which is approximately at two thirds of a line drawn from the umbilicus to the anterior superior iliac spine. ${ }^{64}$

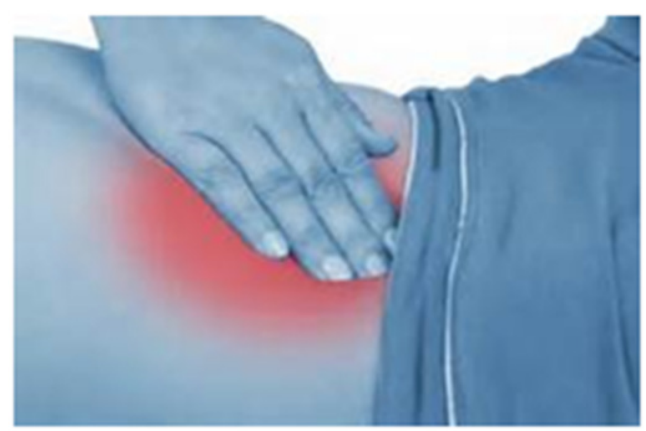

Figure 2 McBurneys' point tenderness in RIF site. ${ }^{64}$

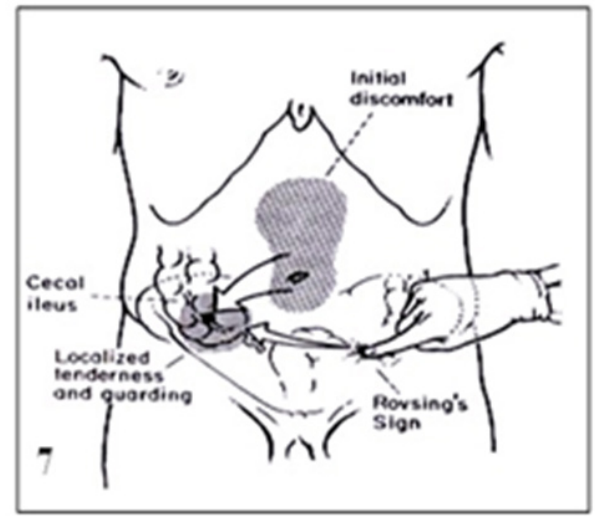

Figure 3 Positive Roving's Sign by palpate LIF exacerbate pain in RIF. ${ }^{64}$

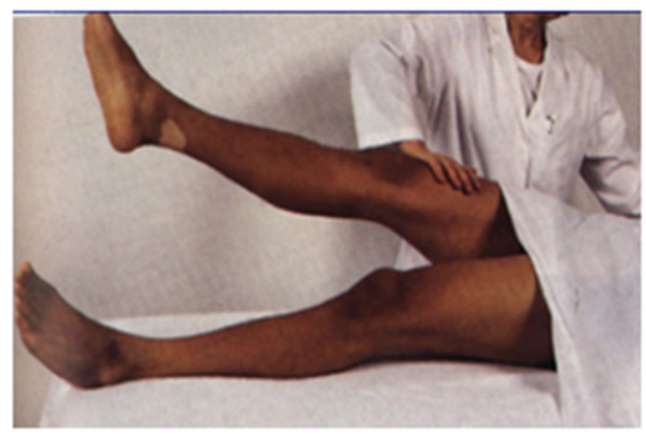

Figure 4 Positive Psoas Sign with flex hip against resistant. 


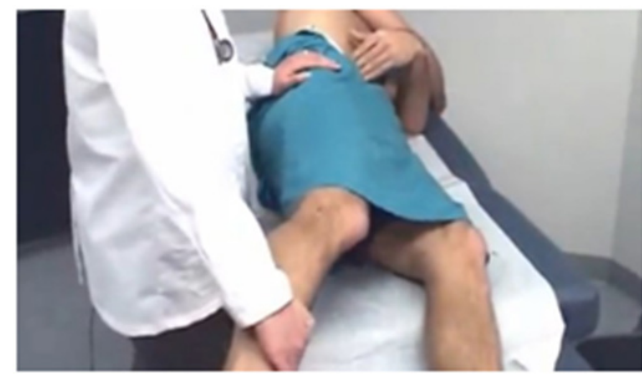

Figure 5 Positive Psoas Sign with backward leg extension. ${ }^{64}$

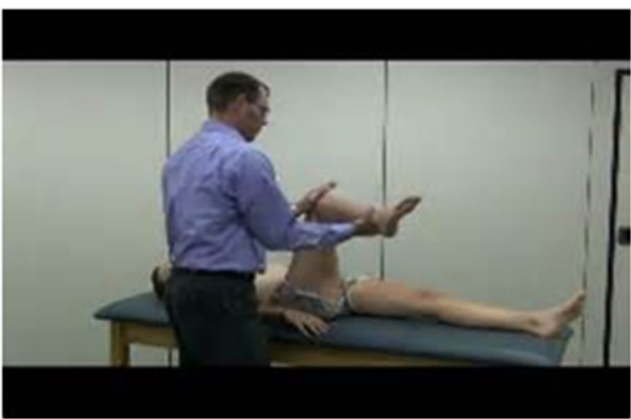

Figure 6 Positive Obturator Sign by flex right knee with internal rotation of the right hip. ${ }^{64}$

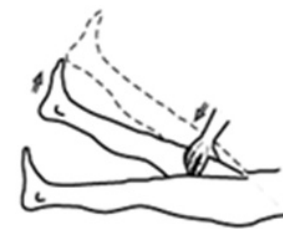

A. lliopsoas test

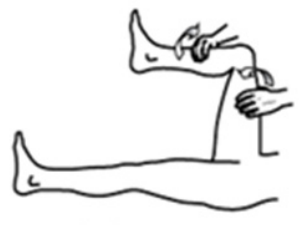

B. Obturator test

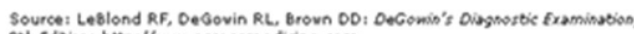

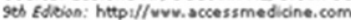

Copyright \& The Mcorar-hall Companies, inc All rights reserved.

Figure 7 Positive Psoas and Obturator Signs . ${ }^{64}$

\section{Laboratory investigations}

The presence or absence of inflammatory markers is either support or refute diagnosis of acute appendicitis such as, increase level of leucocyte/neutrophil/granulocyte and C-reactive protein (CRP). ${ }^{12-15}$ Urine analysis and microscopy can either support or refute urinary tract infection, but it is confusing in pelvic acute appendicitis. ${ }^{16}$ Other important biochemical tests are serum/urine beta HCG, amylase, lipase, liver function tests, and electrolyte levels. Serum bilirubin is potential biomarkers for the diagnosis of acute perforated appendicitis. ${ }^{17}$ Other inflammatory markers of less importance are Interleukin-6; plasma D-lactate levels lactoferrin and calprotectin; have not been shown to aid the diagnosis of acute appendicitis or reduce unnecessary appendectomy. ${ }^{18-20}$

\section{Scoring systems}

Sometimes, there are many difficult cases of acute appendicitis are missed in primary and secondary care. Moreover; there are many negative, unnecessary appendectomies (range $14-75 \%$ ). ${ }^{21}$ Using clinical scoring systems (computer-aided diagnosis algorithm) to improve diagnosis of acute appendicitis based on symptoms, signs and laboratory findings. In suspected adult, use Alvarado Scores (AS) ${ }^{21}$ whereas, in suspected children use Pediatric Appendicitis Scores (PAS) or Samuel Scores (SS). ${ }^{22}$ It will increase the diagnostic accuracy up to $97.2 \%$; also it is shown decrease in the number of appendicular perforations. ${ }^{23,24}$

Alvarado Score or MANTRELS Score ${ }^{1,3}$ : It is simple scoring scales consist of three symptoms, three signs and two inflammatory laboratory markers (Table 4 ) or by using the mnemonic MANTRELS. The total score is 10 ; therefore, a score of $5-6$ is low compatible (required observation), then score of $7-8$ (proceed to radiological investigation) indicating probable, however, score of 9-10 (proceed to surgery) indicating a very probable acute appendicitis. The two most important symptoms with high positive likelihood ratio (LR+) are a history of RIF pain (LR $+=8.0,95 \%$ CI 7.3-8.5) and positive pain migration (LR $+=3.1,95 \%$ CI $2.4-4.2)(\mathrm{LR}+2.1,95 \%$ CI $1.6-$ 2.6). ${ }^{5,10}$ While, anorexia, nausea and vomiting are not alter the LR + of acute appendicitis, whereas, decreased LK with a history of similar previous pain (LR $-=0.3,95 \% \mathrm{CI} 0.2-0.4)$ and with the absence of right lower quadrant pain (LR $-=0.2,95 \%$ CI $0.0-0.3$ ). There are two ways of measurement of scoring scales depend on clinical (signs plus symptoms) and laboratory findings (Table 4: Alvarado and Table 5: Modified Alvarado (MANTRELS) Scoring Scales).

Table 4 Alvarado scoring scale for diagnosis of acute appendicitis. ${ }^{3}$

\begin{tabular}{ll}
\hline Alvarado score & Variable Value \\
\hline Symptoms & \\
Migration & $\mathrm{I}$ \\
Anorexia-acetone & $\mathrm{I}$ \\
Nausea-vomiting & \\
Signs & 2 \\
Tenderness in right lower quadrant & $\mathrm{I}$ \\
Rebound pain & $\mathrm{I}$ \\
Elevation of temperature C 37.3 - & \\
Laboratory & 2 \\
Leukocytosis $>10.0 \times 10^{9} / \mathrm{L}$ & $\mathrm{I}$ \\
Shift to the left $>75 \%$ & 10 \\
Tota* &
\end{tabular}

Table 5 MANTRELS score for diagnosis of acute appendicitis. ${ }^{3}$

\begin{tabular}{ll}
\hline MANTRELS score & Variable Value \\
\hline$M=$ Migration of pain to the RIF & $\mathrm{I}$ \\
$A=$ Anorexia & $\mathrm{I}$ \\
$\mathrm{N}=$ Nausea and vomiting & $\mathrm{I}$ \\
$\mathrm{T}=$ Tenderness in RIF & 2 \\
$\mathrm{R}=$ Rebound pain & $\mathrm{I}$ \\
$\mathrm{E}=$ Elevated temperature & $\mathrm{I}$ \\
$\mathrm{L}=$ Leukocytosis & 2 \\
$\mathrm{~S}=$ Shift of WBCs to the left & $\mathrm{I}$ \\
Total & 10 \\
Source:Alvarado., &
\end{tabular}

*_Total score of I- 4:Appendicitis unlikely; 5 - 6:Appendicitis possible; 7 - 8 : Appendicitis probable; $9-10$ :Appendicitis very probable.

Other Scoring Systems: The use of Tzanakis Scoring System combined with ultrasound scanning along with clinical and laboratory findings (Ultrasound positive for acute appendicitis, tenderness in the right lower quadrant, rebound tenderness and a leukocyte count $\geq 12,000 / \mathrm{L}$ ); aid physician for early diagnosis of appendicitis. ${ }^{20}$ The use of eight independent predictive variables in Appendicitis Inflammatory Response Score (AIRS) (right lower quadrant pain, rebound tenderness, muscular defense, WBC count, proportion of neutrophils, CRP, body temperature and vomiting) with high Sensitivity ( 0.97 vs. 0.92$)$, and Specificity ( 0.93 vs. 0.88 ) to diagnose appendicitis cases. ${ }^{25}$ The use of seven independent 
predictive variables in Ohmann score (right lower quadrant pain, rebound tenderness, no micturition difficulties, steady pain, leukocyte count $\geq 10.0$, age $\leq 50$ years, and positive abdominal rigidity). ${ }^{26}$ The predictive symptoms and signs to diagnosis appendicitis in children by using Lintula score (gender, intensity of pain, relocation of pain, vomiting, pain in the right lower quadrant, fever, guarding, bowel sounds and rebound tenderness); which subsequently been validated in adults. ${ }^{27,28}$ The Fenyo-Lindberg scoring system uses nine clinical and one laboratory variable to form a score to predict cases of appendicitis. ${ }^{29}$

Pediatric Appendicitis Score (PAS) (Samuel score): The use of eight independent predictive variables in The Pediatric Appendicitis Score (PAS) (Cough/percussion/hoping tenderness in the RIF, anorexia, pyrexia, nausea and emesis, tenderness over the right iliac fossa, leukocytosis, polymorph nuclear neutrophil and migration of pain), the score are of sensitivity of 1 , specificity of 0.92 , positive predicted value (PPV) of 0.96 and negative predictive value (NPV) of $0.99 .{ }^{22}$ It is useful in stratifying the clinical risk of children with acute appendicitis by categorizing them as low $(<2)$, while in medium (36) need for further radiological examination (ultrasound or computed tomography) or need for a period of further evaluation, however high risk $(\geq 7)$ of acute appendicitis, ${ }^{30-33}$ while those with an Alvarado score between 3 and 6 should undergo a CT scan of the abdomen (sensitivity of $90.4 \%$ and specificity of $95 \%$ ). ${ }^{32,33}$ None of the scoring systems definitive diagnose acute appendicitis or predict the need for further investigation. Therefore, clinical examination combined with clinical decision and using scoring scales will guide physicians for further investigation in unclear acute appendicitis.

\section{Difficult diagnostic cases}

Extreme of age: Listless infant and confused elderly may present with atypical signs and symptoms of acute appendicitis. So, the physician needs a high index of suspicion in examination of suspected appendicitis in this category. ${ }^{36}$

Appendicitis in children: While acute appendicitis is very common childhood abdominal operation, ${ }^{37}$ but diagnosis of appendicitis in ambulatory care was reaching only $2.3 \%^{38}$ because it remained a challenge for many clinicians..$^{39}$ Early diagnosis of appendicitis will ultimately decrease appendicular perforation, ${ }^{6,17}$ abscess, gangrene, peritonitis and a shortening period of post-operative hospitalization. ${ }^{40,41}$ Usually, there was a delay in diagnosis of acute appendicitis in children $^{42}$ due to misdiagnosis. ${ }^{43,44}$ Misdiagnosis rate was ranging from $7.5 \%$ to $37 \%$ for children ${ }^{45}$ and the reason of misdiagnosis was either acute gastritis or gastroenteritis. ${ }^{46}$ The common age incidence of childhood appendicitis is mostly at $9-12$ years ${ }^{47}$ and the red flag of acute appendicitis in childhood are vomiting, ${ }^{48}$ leukocytosis, high $\mathrm{C}$-reactive protein level ${ }^{49}$ right lower quadrant tenderness. ${ }^{50,51} \mathrm{~A}$ high level of clinical suspicion; may need further investigation by either, abdominal ultra-sonographers (sensitivities range from $85 \%-90 \%$ and specificities range from $95 \%-100 \%$ ) and CT scan which increase diagnostic accuracy and decrease negative laparotomy. ${ }^{51}$

Appendicitis wit urological symptoms: While one third of acute appendicitis may have urological manifested (e.g. right flank pain and dysuria, pyurea $>10$ cells per high-power field) due to abnormal pelvic and retrocecal appendix positions. ${ }^{52}$

Appendicitis in Pregnancy: Usually, a typical appearance of appendicitis is present mostly during late pregnancy; because of appendix displacement from gravid uterus. The common complaints are nausea and vomiting with unspecified tenderness located on the right side of the abdomen (Right lower quadrant pain or mid or even upper right side of the abdomen) is the most common symptom.
Acute appendicitis is common during pregnancy with an incidence of $0.15-2.1$ per 1,000 pregnancies. Early use of either magnetic resonance imaging (MRI) or abdominal ultrasound (US) will increase diagnostic accuracy of acute appendicitis in pregnancy and prevent both maternal $(1-4 \%)$ and fetal $(1.5-35 \%)$ mortality associated with perforation, which may occur more mostly in the third trimester. ${ }^{53-61}$ Missed appendicitis in pregnancy is common in primary care because of unusual presentation (e.g. heartburn, bowel irregularity, flatulence, malaise, or diarrhea, urinary frequency, dysuria or tenesmus and diarrhea).$^{59}$

Appendicitis in women of child bearing age: Moreover, Pelvic pain of women is challenging scenario because of the long list of differential diagnoses ranged from lifesaving condition (e.g., ectopic pregnancy, appendicitis, ruptured ovarian cyst) to fertility-threatening conditions (e.g., pelvic inflammatory disease, ovarian torsion) must be considered. ${ }^{62,63}$ To increase accuracy of early diagnosis of appendicitis and decrease the rate of negative histopathology of appendectomy, we need to identify clinical scoring systems, laboratory and diagnostic imaging. ${ }^{21-29}$

Appendicular abscess/ Appendicular mass: The physician should palpate abdomen for a tender mass at RIF in patient with swinging pyrexia with leukocytosis. The diagnosis was confirmed by either abdominal US or CT scans. ${ }^{64}$

\section{Conclusion}

The diagnosis of acute appendicitis needs good history, thorough examination and basic laboratory study and the requisite high index of suspicion. The scoring scale systems will enhance clinical judgment and increase acute appendicitis diagnostic accuracy.

\section{Acknowledgments}

None.

\section{Conflicts of interest}

None.

\section{Funding}

None.

\section{References}

1. Humes DJ,SimpsonJ.Acuteappendicitis. BMJ.2006;333(7567):530-534

2. Yi Jung Chang, Hsun Chin Chao, Man Shan Kong, et al. Misdiagnosed pediatric appendicitis Misdiagnosed Acute Appendicitis in Children in the Emergency Department. Chang Gung Med J. 2010;33(5):551-557.

3. Old JL, Dusing RW, Yap W, et al. Imaging for Suspected Appendicitis. Am Fam Physician. 2005;71(1):71-78.

4. X Keyzer, PA Gevenois. Imaging of Acute Appendicitis in Adults and Children, Medical Radiology. Diagnostic Imaging DOI: 10.1007. 2012.

5. Wagner JM, McKinney WP, Carpenter JL. Does this patient have appendicitis? JAMA. 1996;276(19):1589-1594.

6. Murphy J. Two thousand operations for appendicitis with deductions from his personal experience. Am J Med Sci. 1904;128:187-211.

7. Cope Z. Early diagnosis of the acute abdomen. (20th edn), Oxford University Press, UK. 2000. p.1-320.

8. McBurney C. Experiences with early operative interference in cases of diseases of the vermiform appendix. NY Med J. 1889;50:676-684.

9. Abbas Al Ubaidi B. Why primary care doctors get sued and how to reduce your risk? J Bahrain Med Soc. 2015;26(2):121-123. 
10. Andersson R. Meta-analysis of the clinical and labora- tory diagnosis of appendicitis. Br J Surg. 2004;91(1):28-37.

11. Dixon JM, Elton, Rainey, et al. Rectal examination in patients with pain in the right lower quadrant of the abdomen. BMJ. 1997; 302(6773):386-388

12. Sack U, Biereder, Elouahidi T, et al. Diagnostic value of blood inflammatory markers for detection of acute appendicitis in children. BMC Surgery. 2006;6:15.

13. Beltrán MA, Almonacid J, Vicencio, et al. Predictive value of white blood cell count and C-reactive protein in children with appendicitis. $J$ Pediatr Surg. 2007;42(7):1208-1214.

14. Kwan KY, Nager AL. Diagnosing pediatric appendicitis: usefulness of laboratory markers. Am J Emerg Med. 2010;28(9):1009-1015.

15. Yang HR, Wang YC, Chung, et al. Laboratory tests in patients with acute appendicitis. ANZ J Surg. 2006;76(1-2):71-74.

16. Puskar, Bedalov, Fridrih, et al. Urinalysis, ultrasound analysis, and renal dynamic scintigraphy in acute appendicitis. Urology. 1995; 45(1):108-112.

17. Estrada J, Petrosyan, Barnhart, et al. Hyperbilirubinemia in appendicitis: a new predictor of perforation. J Gastrointest Surg. 2007; 11(6):714-718

18. Demircan M, Cetin, Uguralp, et al. Plasma D-Lactic acid level: a useful marker to distinguish perforated from acute simple appen- dicitis. Asian J Surg. 2004;27(4):303-305.

19. Duzgun AP, Bugdayci, Sayin, et al. Serum D-lactate: a useful diagnostic marker for acute appendicitis. Hepatogastroenterology. 2007;54(77):1483-1486.

20. Thuijls G, Derikx, Prakken, et al. A pilot study on potential new plasma markers for diagnosis of acute appendicitis. Am J Emerg Med Med. 2011;29(3):256-260.

21. Alvarado A. A practical score for the early diagnosis of acute appendicitis. Ann Emerg Med. 1986;15(5):557-564.

22. Samuel M. Pediatric appendicitis score. J Pediatr Surg 2002;37(6):877-881.

23. Prabhudesai S. Artificial Neural Networks: Useful Aid in Diagnosing Acute Appendicitis. World J Surg. 2008;32(2):305-309.

24. Hsieh $\mathrm{CH}, \mathrm{Lu} \mathrm{RH}$, Lee NH, et al. Novel solutions for an old disease: Diagnosis of acute appendicitis with random forest, support vector machines, and artificial neural networks. Surgery. 2011;149(1):87-93.

25. Andersson M, Andersson R. The appendicitis inflam- matory response score: a tool for the diagnosis of acute appendicitis that outperforms the Alvarado score. World J Surg. 2008;32(8):1843-1849.

26. Ohmann C, Yang Q, Franke C. Diagnostic scores for acute appendicitis. Abdom Pain Study Group. Eur J Surg. 1995;161(4):273-281.

27. Lintula H, Kokki, Pulkkinen, et al. Diagnostic score in acute appendicitis. Validation of a diagnostic score (Lintula score) for adults with suspected appendicitis. Langenbeck's Arch Surg. 2010;395(5):495-500

28. Lintula H, Hannula Kokki, Riikka Kettunen, et al. A diagnostic score for children with suspected appendicitis. Langenbeck's Arch Surg. 2005;390(2):164-170.

29. Fenyo G, Lindberg, Blind, et al. Diagnostic decision support in suspected acute appendicitis: validation of a simplified scoring system. Eur J Surg. 1997;163(11):831-838.

30. Goldman RD, Carter, Stephens, et al. Prospective validation of the pediatric appendicitis score. J Pediatr. 2008;153(2):278-282.

31. Schneider C, Kharbanda A and Bachur R. Evaluating Appendicitis Scoring Systems Using a Prospective Pediatric Cohort. Annals of Emergency Medicine. 2007;49(6):778-784.
32. Mandeville K, Pottker T, and Bulloch B. Using appendicitis scores in the pediatric ED. Am J Emerg Med. 2010;29(9):972-977.

33. Bhatt M, Joesph, Ducharme, et al. Prospective validation of the pediatric appendicitis score in a canadian pediatric emergency department. Acad Emerg Med. 2009;16(7):591-596.

34. McKay R, Shepherd J. The use of the clinical scoring system by Alvarado in the decision to perform computed tomography for acute appendicitis in the ED. Am J Emerg Med. 2007;25(5):489-493.

35. Pouget-Baudry Y, Mucci, Eyssartier, et al. The use of the Alvarado score in the management of right lower quadrant abdominal pain in the adult. Journal of Visceral Surgery. 2010;147(2):e40-e44.

36. Paulson EK, Kalady MF, Pappas TN. Suspected appendicitis. $N$ Engl $J$ Med. 2003;348(3):236-242.

37. Hartman GE. Acute appendicitis. In: Behrman RE, Kleigman RM, Jenson HB, (Eds). Nelson Textbook of Pediatrics. (18th edn), Saunders, Philadelphia, USA. 2007. p.1628-1634

38. McCollugh M, Sharieff GQ. Abdominal pain in children. Pediatr Clin North Am. 2006;53(1):107-137.

39. Becker T, Kharbanda A, Bachur R. Atypical clinical features of pediatric appendicitis. Acad Emerg Med. 2007;14(2):124-129.

40. Rothrock SG, Pagane J. Acute appendicitis in children: emergency department diagnosis and management. Ann Emerg Med. 2007;36(1):39-51.

41. Reynolds SL. Missed appendicitis in a pediatric emergency department. Pediatr Emerg Care. 1993;9(1):1-3.

42. Nelson DS, Bateman B, Bolte RG. Appendiceal perforation in children diagnosed in a pediatric emergency department. Pediatr Emerg Care. 2000;16(4):233-237.

43. Velanovich V, Satava R. Balancing the normal appendectomy rate with the perforated appendicitis rate: implications for quality assurance. $A m$ Surg. 1992;58(4):264-269.

44. Kosloske AM, Love CL, Rohrer JE, et al. The diagnosis of appendicitis in children: outcome of a strategy based on pediatric surgical evaluation. Pediatrics. 2004;113(1 pt 1):29-34.

45. Rothrock SG, Skeoch G, Rush JJ, et al. Clinical features of misdiagnosed appendicitis in children. Ann Emerg Med. 1991;20(1):45-50.

46. D’Agostino J. Common abdominal emergencies in children. Emerg Med Clin North Am. 2002;20(1):139-153.

47. Chen SY, Tsai CN, Lai MW, et al. Norovirus infection as a cause of diarrhea-associated benign infantile seizure. Clin Infect Dis. 2009;48(7):849-855

48. Pearl RH, Hale DA, Molloy M, et al. Pediatric appendectomy. J Pediatr Surg. 1995;30:173.

49. Davenport M, Acute abdomen pain in children. BMJ. 312:498-501.

50. Beltran MA, Almonacid J, Vicencio A, et al. Predictive value of white blood cell count and C-reactive protein in children with appendicitis. $J$ Pediatr Surg . 2007;42(7):1208-1214.

51. Colvin JM, Bachur R, Kharbanda A. The presentation of appendicitis in preadolescent children. Pediatr Emerg Care. 2007;23(12): 849-855.

52. Rao PM, Rhea JT, Rattener DW. Introduction of appendiceal CT: impact on negative appendectomy and appendiceal perforation rates. Ann Surg. 1999;229(3):344-349.

53. Tundidor Bermúdez AM, Amado Diéguez JA, Montes de Oca Mastrapa JL. Urological manifestations of acute appendicitis. Arch Esp Urol. $2005 ; 58(3): 207-212$

54. Weingold AB. Appendicitis in pregnancy. Clin Obstet Gynecol 1983;26:801. 
55. Mourad J, Elliott JP, Erickson L, et al. Appendicitis in pregnancy: new information that contradicts long-held clinical beliefs. Am J Obstet Gynecol. 2000;182(5):1027-1029.

56. Hodjati H, Kazerooni T. Location of the appendix in the gravid patient: a re-evaluation of the established concept. Int $J$ Gynaecol Obstet. 2003;81(3):245-247.

57. Popkin CA, Lopez PP, Cohn SM, et al. The incision of choice for pregnant women with appendicitis is through McBurney's point. Am J Surg. 2002;183(1):20-22.

58. Oto A, Srinivasan PN, Ernst RD, et al. Revisiting MRI for appendix location during pregnancy. AJR Am J Roentgenol. 2006;186(3):883-887.
59. Pates JA, Avendanio TC, Zaretsky MV, et al. The appendix in pregnancy: confirming historical observations with a contemporary modality. Obstet Gynecol. 2009; 114(4):805-808.

60. House JB, Bourne CL, Seymour HM, et al. Location of the appendix in the gravid patient. J Emerg Med. 2014;46(5):741.

61. http://www.uptodate.com/contents/acute-appendicitis-in-pregnancy

62. Guttman R, Goldman RD, Koren G. Appendicitis during pregnancy. Can Fam Physician. 2004;50:355-357.

63. Kruszka PS, Kruszka SJ. Evaluation of Acute Pelvic Pain in Women American Family Physician. 2010;82(2):141_147.

64. Humes DJ, SimpsonJ.Acuteappendicitis. BMJ.2006;333(7567):530-534. 